\title{
ANÁLISE ESTATÍSTICA APLICADA AOS PARÂMETROS DE SÍNTESE DE FAUJASITA Na-X
}

\author{
M. S. CASTRO ${ }^{1}$, W. M. FANTIM ${ }^{1}$, R. CONDOTTA ${ }^{1}$, E. L. GOMES ${ }^{2}$, J. G. R. POÇO ${ }^{1, *}$ \\ ${ }^{1}$ Centro Universitário FEI, Departamento de Engenharia Química \\ ${ }^{2}$ Universidade Federal de São Paulo, Departamento de Ciências Exatas e da Terra \\ *E-mail: jgrpoco@fei.edu.br
}

\begin{abstract}
RESUMO: Devido às sua estrutura altamente regular e características microporos com dimensões regulares e superfície específica, as zeólitas, especialmente as sintéticas tem encontrado várias aplicações industriais como componentes em catalisadores heterogêneos. Entretanto, em muitas das aplicações petroquímicas, a estrutura microporosa impõe limitações à difusão das moléculas de reagentes e produtos e se torna um problema. Muito esforço de pesquisa na síntese de outras estruturas zeolíticas com diâmetros de microporos mais largos ou estruturas mistas contendo micro e mesoporos tem sido feito. Neste estudo, foi realizado um delineamento experimental baseado na metodologia de Placket \& Burman para selecionar as variáveis que tem maior efeito na síntese de zeólita do tipo faujasita (FAU-X) com baixa relação molar $\mathrm{SiO}_{2} / \mathrm{Al}_{2} \mathrm{O} 3$ para posteriormente fixar as melhores condições $e$ verificar o efeito da introdução de partículas funcionalizadas de carbono nanométricas na geração de estruturas mesoporosas.
\end{abstract}

PALAVRAS-CHAVE: Zeólita X; Plackett\&Burman; Variáveis de Síntese; Seleção de variáveis.

\section{INTRODUÇÃO}

As zeólitas são aluminossilicatos cristalinos cujas estruturas são formados pela combinação de tetraedros de silicato $\left(\mathrm{SiO}_{4}\right)$ com tetraedros de aluminato $\left(\mathrm{AlO}_{4}{ }^{-}\right)$na qual o balanço de cargas elétricas é obtido com a neutralização com metais alcalinos ou alcalinoterrosos. Podem ser representados pela fórmula química $\mathrm{M}_{2 / n} \mathrm{O} \cdot \mathrm{Al}_{2} \mathrm{O}_{3} \cdot \mathrm{ySiO}_{2} \cdot \mathrm{wH}_{2} \mathrm{O}$, onde y $>=2$, $M$ é o cátion de balanceamento da carga, tais como sódio, potássio, magnésio e cálcio, " $n$ " é a valência do cátion, e w representa o número de mols de água. As estruturas contêm espaços vazios interconectados que estão ocupados pelos cátions e as moléculas de água contida nos espaços vazios interconectados formando canais (ERTL et al., 2008). A água pode ser removida de forma reversível, geralmente pela aplicação de calor, deixando intacta a estrutura cristalina permeada com microporos que podem contabilizar mais de $50 \%$ do volume do microcristal (BRECK, 1974; GIANNETTO, 1990).

As zeólitas foram descobertas como um novo tipo de mineral em 1756 pelo mineralogista sueco A. F. Cronstedt (BRECK, 1974). A palavra "zeolite" foi derivada de duas palavras gregas que significam pedra que ferve (PLUTH e SMITH, 1991). Mais de 200 tipos 
de zeólitas sintéticas e 50 zeólitas naturais são conhecidos (SAND e MUMPTON, 1978). A nomenclatura dos minerais de zeólita seguem procedimentos estabelecidos pela Associação Internacional de Zeólitas. Ambas as topologias diferentes de zeólitas sintéticos e naturais recebem códigos de três letras. Os tipos mais comuns de estruturas minerais incluem a analcima (ANA), clinoptilolita (HEU), mordenita (MOR), chabazita (CHA), erionita (ERI) e phillipsita (PHI) com poucas aplicações e os tipos sintéticos mais conhecidos e com maior aplicação industrial são os tipos LTA (A), FAU (X, Y), MFI (ZSM-5), MOR (mordenita) dentre outros (BAERLOCHER; MCCUSKER; OLSON, 2007).

\subsection{Sintese de zeólitas}

As zeólitas sintéticas são formadas sob condições hidrotermais, fora do equilíbrio e são consideradas como fases metaestáveis no sentido termodinâmico. Geralmente são usadas matérias primas reativas tais como géis recentemente co-precipitados ou sólidos amorfos; relativamente elevado $\mathrm{pH}$ introduzido sob a forma de um hidróxido de metal alcalino ou outra base forte, incluindo hidróxidos de tetra-alquilamônio; condições hidrotermais de baixa temperatura com simultânea baixa pressão autógena a pressão de vapor de água saturado; e um alto grau de supersaturação dos componentes do gel, levando a nucleação de um grande número de cristais (DETÍLIO, 2007).

Um dos reagentes mais utilizados como fonte de Al na síntese de zeólitas do tipo faujasita $\mathrm{X}$ é o aluminato de sódio, no qual os átomos estão na forma aniônica. $\mathrm{O} \mathrm{NaAlO}_{2}$ é produzido a partir de $\mathrm{Al}(\mathrm{OH})_{3}$, que por sua vez, é obtido por meio da purificação da bauxita, pelo processo Bayer (CORSO et al., 2014).

Quando preparado, o gel de silicato de alumínio tem diferentes aparências, de duro e translúcido a precipitados gelatinosos opacos e misturas heterogêneas de um sólido amorfo dispersos em solução aquosa. Os metais alcalinos formam em hidróxidos, silicatos e aluminatos solúveis que são materiais adequados para a preparação de misturas homogêneas (JACOBSEN et al., 2000).

Corso et al. (2014) estudaram a síntese de zeólita do tipo X ou faujasita X (FAU - X) realizando um planejamento experimental onde foram variadas as relações molares características $\mathrm{SiO}_{2} / \mathrm{Al}_{2} \mathrm{O}_{3} ; \mathrm{Na}_{2} / \mathrm{Al}_{2} \mathrm{O}_{3}$ e $\mathrm{H}_{2} \mathrm{O} / \mathrm{Al}_{2} \mathrm{O}_{3}$ segundo um fatorial $2^{3}$ tendo encontrado que as melhores relações de composição de síntese para obtenção de faujasita $\mathrm{X}$ pura foram respectivamente 3,0; 4,2 e 195,7. Entretanto o tipo de equipamento empregado e demais condições para a preparação do gel não foram citadas ou estudadas.

Este trabalho tem por objetivo principal sintetizar zeólitas $X$ (da família das faujasitas) com alta cristalinidade, com materiais carbonosos ocluídos na estrutura cristalina para promover a geração de mesoporosidade interna nos cristais, após calcinação. Outrossim, para atingir o objetivo principal, fazem parte dos objetivos desta proposta aplicar um método estatístico para selecionar as variáveis mais importantes dentre algumas selecionadas e que podem ter influência na cristalinidade e outras propriedades das zeólitas X. Sintetizar zeólitas nas condições selecionadas com adição de partículas de carbono funcionalizadas. 


\section{MATERIAIS E MÉTODOS}

A metodologia empregada nas preparações de zeólita $\mathrm{X}$ foram baseadas na literatura (BRECK, 1974) na qual em primeiro lugar é realizada a mistura de uma fonte dos íons aluminato, uma fonte de íons silicato e dos cátions de compensação formando um gel de consistência que variável entre líquido e sólido. Depois o gel é deixado envelhecer em uma temperatura conveniente por tempo determinados.

Supondo que todas as variáveis empregadas na preparação podem ter algum efeito na cristalinidade, para determinar as melhores condições de síntese, utilizou-se o método Placket e Burman (1946) de seleção de variáveis para verificar quais dentre as escolhidas para este estudo teriam real influência na síntese.

As variáveis escolhidas e os níveis que foram estudados encontram-se na Tabela 1. Foram selecionadas 8 variáveis, e neste projeto escolheu-se o plano (PB) para 11 variáveis sendo três fictícias (CASSA, 1976) ou inertes (RODRIGUES \& IEMMA, 2015) com um total de doze ensaios. Seguindo o método (PB) utilizado (CASSA, 1976) foi construída a Tabela 2 sorteando-se a ordem dessas variáveis e o nível das mesmas em cada experimento.

Tabela 1 - Variáveis e níveis utilizados para avaliação dos efeitos por Placket e Burman

\begin{tabular}{|c|c|c|c|}
\hline & Variáveis & + & - \\
\hline F1 & Fictícia/Inerte 1 & & \\
\hline F2 & Fictícia/Inerte 2 & & \\
\hline F3 & Fictícia/Inerte 3 & & \\
\hline V1 & Rotação do agitador & $800-1000$ & $300-500$ \\
\hline $\mathbf{V} 2$ & Tempo de agitação & $\sim=2 \min$ & $5 \mathrm{~min}$ \\
\hline $\mathbf{V 3}$ & Tempo de envelhecimento & $22-24 \mathrm{~h}$ & $<5 \min$ \\
\hline V4 & Tipo de impelidor & Serra dentada & Hélice \\
\hline V5 & Tempo de cristalização & $22-24 \mathrm{~h}$ & $4 \mathrm{~h}$ \\
\hline V6 & Tempo de adição & $5 \mathrm{~min}$ & $0,5-1 \mathrm{~min}$ \\
\hline V7 & Ordem da mistura & A $->S$ & $S->$ A \\
\hline V8 & Presença de sementes & $\operatorname{Sim}(0,1 \mathrm{~g})$ & Não \\
\hline
\end{tabular}

Os ensaios foram realizados com a composição química dos reagentes foram baseadas naquelas utilizadas por Corso et al. (2014). Primeiramente, a solução de aluminato de sódio que seria utilizada na síntese foi preparada em um béquer de aço pela adição de 73,6 $\mathrm{g}$ de $\mathrm{Al}(\mathrm{OH})_{3}, 148,8 \mathrm{~g}$ de $\mathrm{NaOH}$ e $500 \mathrm{ml}$ de água. A mistura foi agitada até total dissolução e em seguida aquecida a $100{ }^{\circ} \mathrm{C}$ sob constante agitação, utilizando um agitador mecânico com impelidor do tipo serra dentada a $300 \mathrm{rpm}$, permaneceu nesse sistema por aproximadamente 1 h e $50 \mathrm{~min}$, até que a mistura passasse de esbranquiçada para transparente, e então estava pronta para ser utilizada na síntese. A solução utilizada na síntese contém $59 \mathrm{~g}$ da solução de aluminato de sódio juntamente a 97, g de água deionizada. 
Tabela 2: Níveis das variáveis para cada ensaio.

\begin{tabular}{cccccccccccc}
\hline & F2 & F1 & V3 & V4 & V5 & V6 & V1 & F3 & V2 & V7 & V8 \\
\hline $\mathbf{1}$ & + & + & - & + & + & + & - & - & - & + & - \\
$\mathbf{2}$ & + & - & + & + & + & - & - & - & + & - & + \\
$\mathbf{3}$ & - & + & + & + & - & - & - & + & - & + & + \\
$\mathbf{4}$ & + & + & + & - & - & - & + & - & + & + & - \\
$\mathbf{5}$ & + & + & - & - & - & + & - & + & + & - & + \\
$\mathbf{6}$ & + & - & - & - & + & - & + & + & - & + & + \\
$\mathbf{7}$ & - & - & - & + & - & + & + & - & + & + & + \\
$\mathbf{8}$ & - & - & + & - & + & + & - & + & + & + & - \\
$\mathbf{9}$ & - & + & - & + & + & - & + & + & + & - & - \\
$\mathbf{1 0}$ & + & - & + & + & - & + & + & + & - & - & - \\
$\mathbf{1 1}$ & - & + & + & - & + & + & + & - & - & - & + \\
$\mathbf{1 2}$ & - & - & - & - & - & - & - & - & - & - & - \\
\hline
\end{tabular}

A suspensão gelatinosa inicial para a cristalização da zeólita, foi realizada pela adição da solução de aluminato de sódio e água, na solução de silicato de sódio $(29,11$ g) (nível +) ou da solução de silicato de sódio na solução de aluminato de sódio e água (nível -), também foi acrescentou uma amostra de zeólita X considerada padrão com a função de ser vir como "semente" na solução de silicato $(0,1 \mathrm{~g})$ (nível + ), ou não era acrescentado nenhum tipo de semente (nível -). A mistura foi feita em um béquer de polipropileno provido com um agitador mecânico com impelidor usando "serra dentada' (nível +) ou "hélice marítima" (nível -) e a rotação do impelidor ficava na faixa de 800 a 1000 rpm (nível +) ou 300 a 500 rpm (nível -). Após a agitação o gel formado foi mantido em repouso por [ $23 \mathrm{~h}($ nível + ) ou $\sim 5$ min (nível -), sendo posteriormente colocada na estufa a $110{ }^{\circ} \mathrm{C}$ permanecendo por tempo de aproximadamente 24 h (nível +) ou $\sim 4$ h (nível -).

Ao fim do período de cristalização as amostras foram filtradas a vácuo e lavadas com água destilada até que o efluente do filtro estivesse na ordem de $\mathrm{pH} 10$, em seguida o sólido resultante da filtração foi levado em uma placa de Petri, para a estufa para secagem a $110{ }^{\circ} \mathrm{C}$, ficando por um período entre 20 e $24 \mathrm{~h}$. O procedimento pode ser observado com maior clareza pelo fluxograma da Figura 1.

A calcinação das amostras foi realizada aquecendo inicialmente a mufla a ser utilizada até $200{ }^{\circ} \mathrm{C}$ em seguida as amostras secas foram colocadas em cadinhos de porcelana e a temperatura elevada para $350{ }^{\circ} \mathrm{C}$. Os cadinhos permaneceram na mufla por $1 \mathrm{~h}$ e após esse período foram retirados cuidadosamente e dispostos em um dessecador, onde ficaram por aproximadamente $24 \mathrm{~h}$. Para efeito de comparação calcinou-se também uma amostra de zeólita X considerada padrão.

As zeólitas cristalinas adsorvem fortemente moléculas que são pequenas o suficiente para penetrar suas redes cristalinas e assim, a adsorção tem sido muito utilizada para determinar volumes intracristalinos de zeólitos puros (BENESI, 1975). O rendimento e a pureza cristalina são melhor avaliados por adsorção do que por difração de raios-X porque a umidade pode interferir na forma e nos ângulos dos picos apresentados no difratograma. De acordo com as normas ASTM para faujasitas (CHUNG e SMITH, 1999) as amostras devem ser analisadas num ambiente com $35 \%$ de umidade constante condição que não era possível 
de ser obtida no difratômetro utilizado.

Assim, após as amostras foram pesadas e levadas a um dessecador no qual a sílica que ficava no fundo do mesmo foi substituída por uma solução de $600 \mathrm{~mL}$ de vaselina com $20 \mathrm{~g}$ de tolueno de forma a manter uma baixa pressão de saturação. O tolueno foi selecionado com adsorbato pois o diâmetro de suas moléculas não permite que elas sejam adsorvidas por poros com diâmetros menores que o da estrutura cristalina esperada (BENESI, 1975).

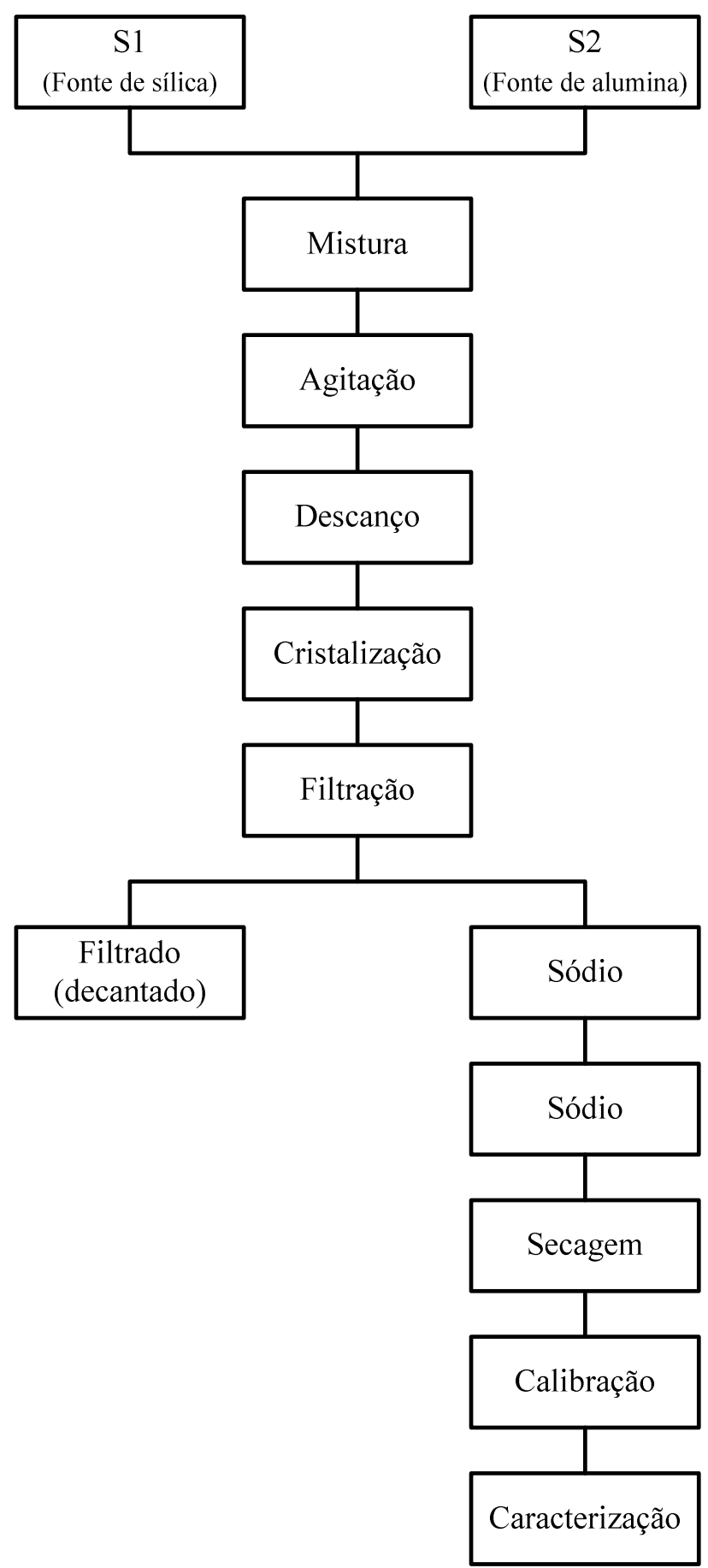

Figura 1 - Fluxograma das sínteses de zeólita X utilizadas neste trabalho 

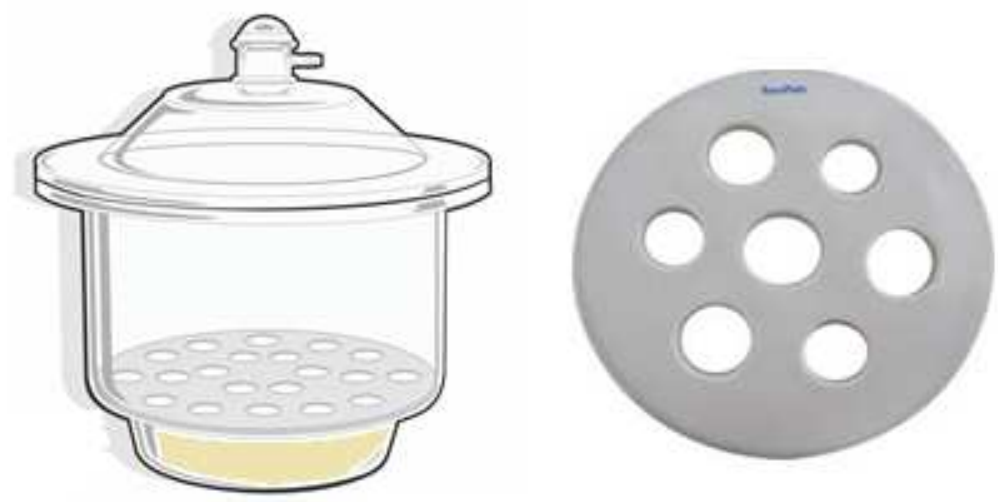

Figura 2 - Representação do dessecador utilizado para avaliar a cristalinidade por adsorção

Os cadinhos foram mantidos por 18 dias dentro do dessecador (Figura 2), e durante esse período foram pesadas por 9 vezes, em intervalos de 1 a 7 dias para verificação da porcentagem adsorvida de tolueno nos poros das zeólitas sintetizadas.

A difração de raios-X foi empregada para confirmar a estrutura apenas nas amostras com maior cristalinidade avaliada por adsorção.

Depois de identificar o efeito das variáveis estudadas, foi selecionada a melhor condição de síntese e foram elaborados planejamentos específicos visando a introdução das formas de carbono preparados segundo métodos publicados (DETÍLIO, 2007), na geração de mesoporosidade nos cristais de zeólitas do tipo de estrutura estudada.

\subsection{Avaliação dos Efeitos}

O método de Placket-Burman (1946 apud CASSA, 1976) possibilita a identificação da interação entre dois ou mais fatores e a influência desta interação nos efeitos das variáveis primárias. O delineamento Plackett-Burman é classificado como delineamento fatorial fracionado de dois níveis, seus arranjos são criados em tamanhos múltiplos de quatro, compostos de sinais positivos para os níveis superiores, e sinais negativos para os níveis inferiores. Admite-se que uma variável é estatisticamente significativa quando o efeito produzido pela variação dos níveis desta variável apresenta um grau e confiança superior a 90 $\%$.

Neste trabalho utilizou-se a metodologia descrita por Rodrigues e Iemma (2015). Primeiro, avalia-se a média global dos resultados das medidas da variável independente. Para cada efeito, realiza-se a somatória do valor da variável independente com o sinal (+) ou (-) associado à resposta. $\mathrm{O}$ resultado é dividido pelo número total de experimentos. Calcula-se o valor de t para a relação efeito/erro padrão e determina-se o valor de p para determinar o nível de significância. O erro padrão é calculado pelo erro das variáveis fictícias ou inertes.

\subsection{Funcionalização de Partículas de Carbono (XC72-R)}

Amostras de carbono submicrométrico XC72-R (CABOT, 1989) normalmente utilizadas como suporte para catalisadores em células a combustível (fuel cells), foram 
tratadas baseadas em procedimentos descritos na literatura, Carmo, Linardi e Poço (2008 e 2009) e Carmo et al. (2011).

Foram realizadas duas preparações de zeólita X, utilizando o procedimento já descrito, e os melhores parâmetros de síntese. Demonstrados na Tabela 4 (ver item 5). No primeiro ensaio adicionou-se o carbono tratado com o peróxido e no outro ensaio o carbono tratado com o ácido nítrico.

As amostras foram calcinadas após a secagem juntamente com a amostra padrão, foram colocadas em cadinhos de porcelana e calcinadas em uma mufla aquecida inicialmente a 200 ${ }^{\circ} \mathrm{C}$. Em seguida a temperatura da mufla foi aumentada a uma taxa de $100-150{ }^{\circ} \mathrm{C}$ por hora até $550{ }^{\circ} \mathrm{C}$ permanecendo nessa temperatura por um período de $3 \mathrm{~h}$.

As amostras incluindo o padrão foram analisadas por difração de raios-X varrendo ângulos de 2 a 60 , sendo lido $1^{\circ}$ por minuto. As amostras não tratadas foram analisadas por microscopia eletrônica de varredura (MEV) para identificar possíveis fases estranhas e a presença das partículas de carbono.

\section{RESULTADOS E DISCUSSÃO}

A Figura 3 mostra o aumento da quantidade adsorvida de tolueno em termos percentuais para a amostra 2 em função do tempo. E a Tabela 3 a quantidade de tolueno adsorvida nas amostras do estudo após um período de tempo $525 \mathrm{~h}$. A incerteza da medida é da ordem de $0,7 \%$.

Tabela 3 - Quantidade de tolueno adsorvida (\%) nas amostras preparadas.

\begin{tabular}{cc}
\hline Amostra & Tolueno adsorvido (\%) \\
\hline 1 & 14,85 \\
2 & 14,75 \\
3 & 12,26 \\
4 & 2,23 \\
5 & 0,42 \\
6 & 16,10 \\
7 & 0,11 \\
8 & 16,83 \\
9 & 16,32 \\
10 & 0,14 \\
11 & 12,10 \\
12 & 0,36 \\
\hline
\end{tabular}




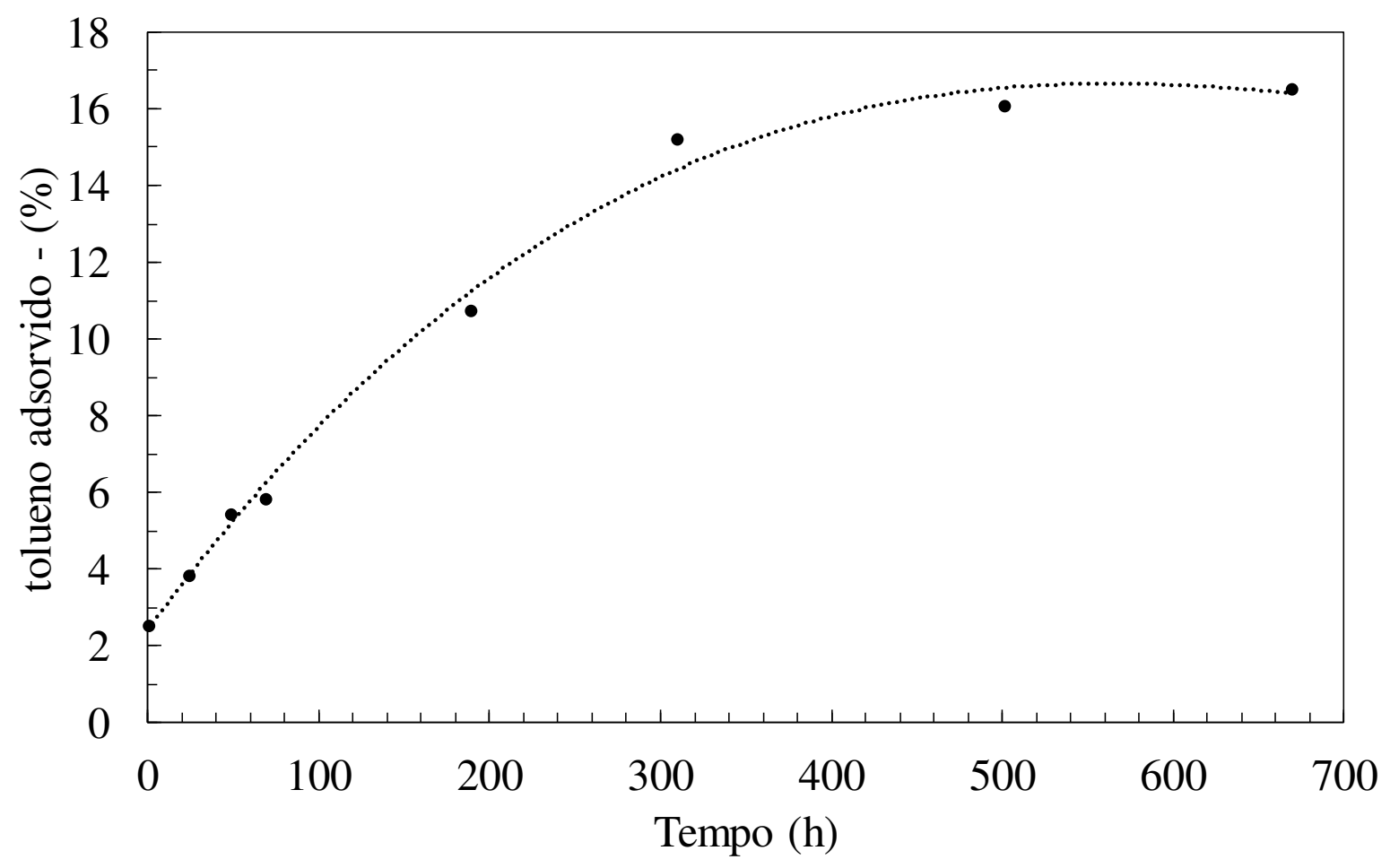

Figura 3 - Exemplo de evolução da \% adsorvida de tolueno em função do tempo (Amostra 6)

O resultado do teste estatístico Placket e Burman de seleção de variáveis esta apresentado na Tabela 4. Com base nos resultados verifica-se a variável com maior efeito nesse planejamento é oi tempo de cristalização com uma probabilidade (p) maior que $95 \%$. Os outros dois efeitos menos significativos, ou seja, com $p>90 \%$ foram que a solução de aluminato deve ser adicionada sobre a solução de silicato em um tempo menor que 1 minuto.

Analisando os gráficos obtidos por DR-X observa-se a existência de alguns picos, que estão indicados na Figura 4, nas amostras de zeólita X contendo carbono tratado com ácido nítrico e peróxido de hidrogênio, calcinadas, e verifica-se que estes mesmos picos não existem nas amostras de zeólita $\mathrm{X}$ que não continham carbono, conforme observado na referência (YANG e DU, 2009) o que indica uma contaminação de fase de zeólita A.

Verificou-se também que as principais diferenças entre a zeólita $\mathrm{X}$ padrão calcinada a $350{ }^{\circ} \mathrm{C}$ e $550{ }^{\circ} \mathrm{C}$ consistem no fato de que a $550{ }^{\circ} \mathrm{C}$ a fase cristalina da zeólita $\mathrm{X}$ é destruída, pois essa, não resiste a temperaturas acima de $350{ }^{\circ} \mathrm{C}$, por isso apresenta picos de menor intensidade.

Na Figura 5 é apresentada a imagem de elétrons secundários, cristais de zeólita X com tamanho entre 2 e $3 \mu \mathrm{m}$, alguns cristais cúbicos característicos da fase zeólita A e apresentam algumas aglomerações como mostrado mais claramente na Figura 6. Entretanto não é possível verificar eventuais orifícios que seriam deixados caso partículas de carbono houvessem entrado na estrutura do cristal. Mesmo na amostra não calcinada (Figuras 7 e 8 ) a presença de carbono não pode ser confirmada. 
Tabela 4 - Tabela dos Efeitos conforme metodologia de Rodrigues \& Iemma (2015)

\begin{tabular}{cccccc}
\hline Variáveis & Efeito & $\begin{array}{c}\text { Erro } \\
\text { padrão }\end{array}$ & $\begin{array}{c}\text { t } \\
\text { calculado }\end{array}$ & $\begin{array}{c}\text { Valor de } \\
\text { p }\end{array}$ & $\begin{array}{c}\text { Análise Estatística } \\
\text { (para aumentar a \% de adsorção } \\
\text { de tolueno nas zeólitas) }\end{array}$ \\
\hline Média & 8.87 & 0.62 & 14.28 & 0.0001 & NES \\
V1 & -2.08 & 1.24 & -1.67 & 0.1697 & NES \\
V2 & -0.86 & 1.24 & -0.69 & 0.5276 & NES \\
V3 & 1.69 & 1.24 & 1.36 & 0.2450 & NES \\
V4 & 1.73 & 1.24 & 1.39 & 0.2358 & AE1 \\
V5 & 12.57 & 1.24 & 10.12 & 0.0005 & AE2 \\
V6 & -2.93 & 1.24 & -2.36 & 0.0779 & AE3 \\
V7 & 3.05 & 1.24 & 2.45 & 0.0702 & NES \\
V8 & 0.84 & 1.24 & 0.67 & 0.5383 & \\
\hline Legenda: NES - Não Estatisticamente Significativo; AE1- Tempo de cristalização de 22- 24 h; AE2 - Tempo \\
de mistura < 1 min; AE3 - A solução de aluminato deve ser adicionada à de silicato \\
\hline \multicolumn{7}{c}{ p-valor < 0,05 (95\% de confiança) } \\
p-valor < 0,10 (90\% de confiança) \\
p-valor > 0,10 (NES)
\end{tabular}

Experimentos de adsorção não foram realizados para detectar a presença de mesoporos formados pela saída das partículas de carbono (DETILIO, 2007) após a calcinação, porque o colapso da estrutura durante a calcinação pode interferir na estrutura porosa dos cristais.

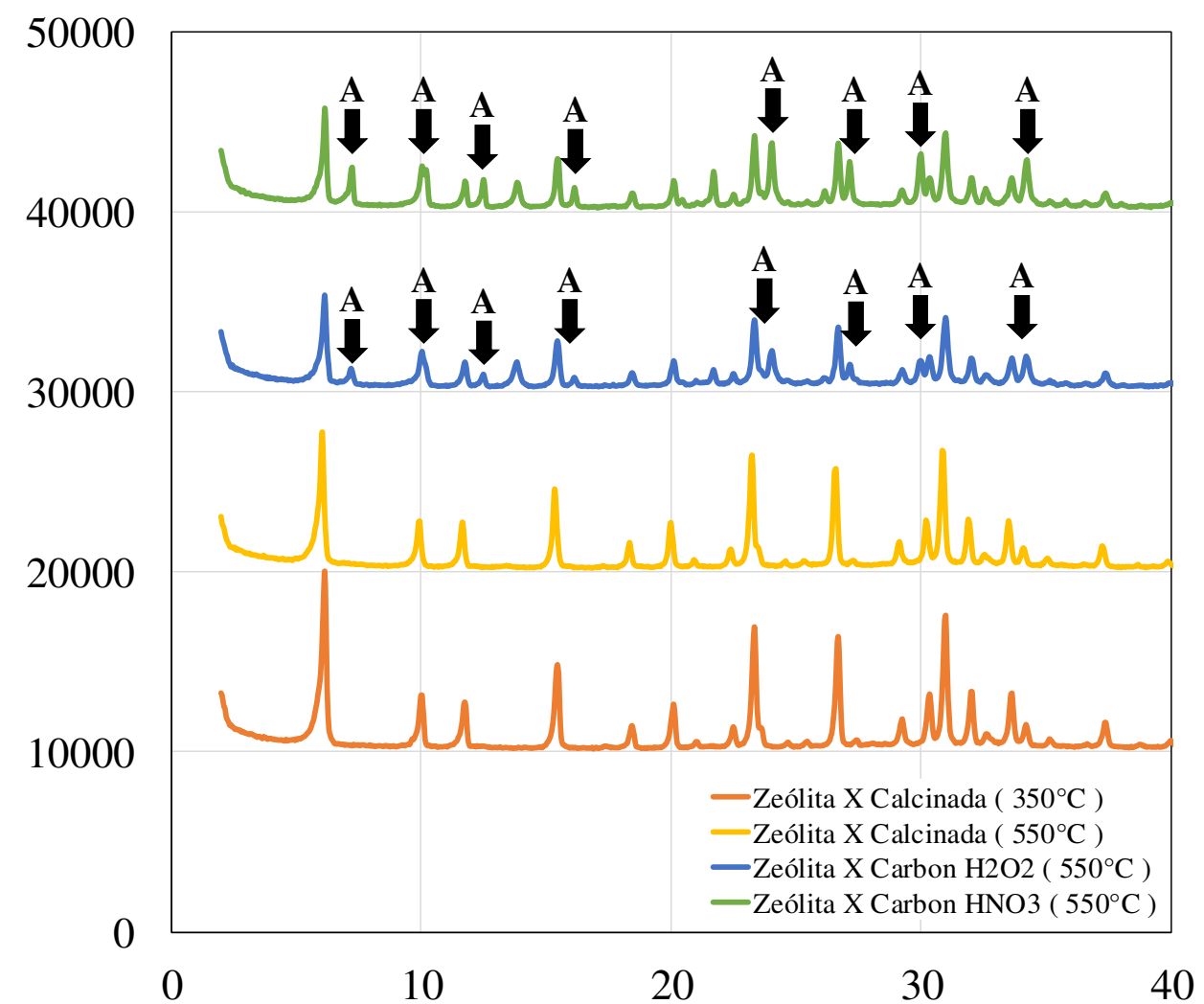

Figura 4 - Análise realizada por difração de Raios-X (Ressaltou-se os picos de maior intensidade da Zeólita A contaminante) 


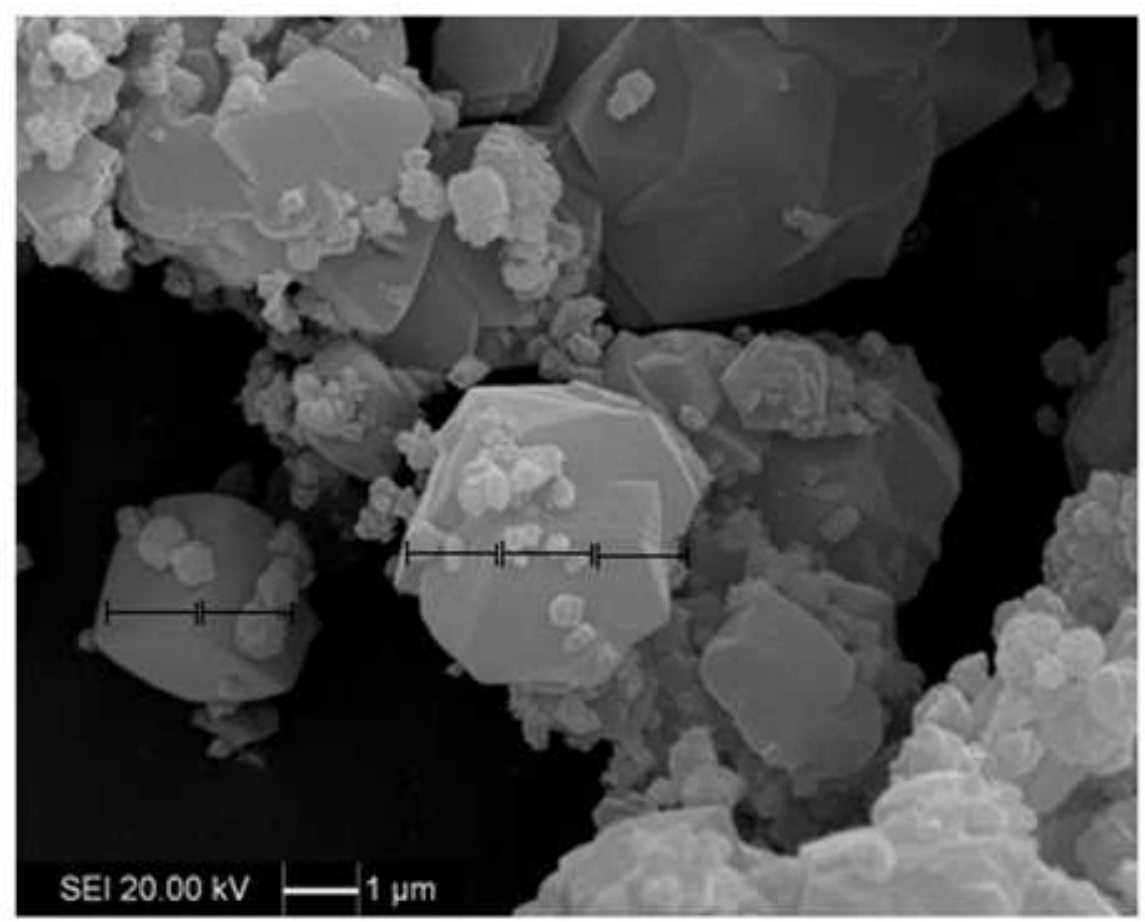

Figura 5 - Imagem de elétrons secundários da amostra de zeólita X cristalizada com XC72-R tratado com ácido nítrico e depois calcinada.

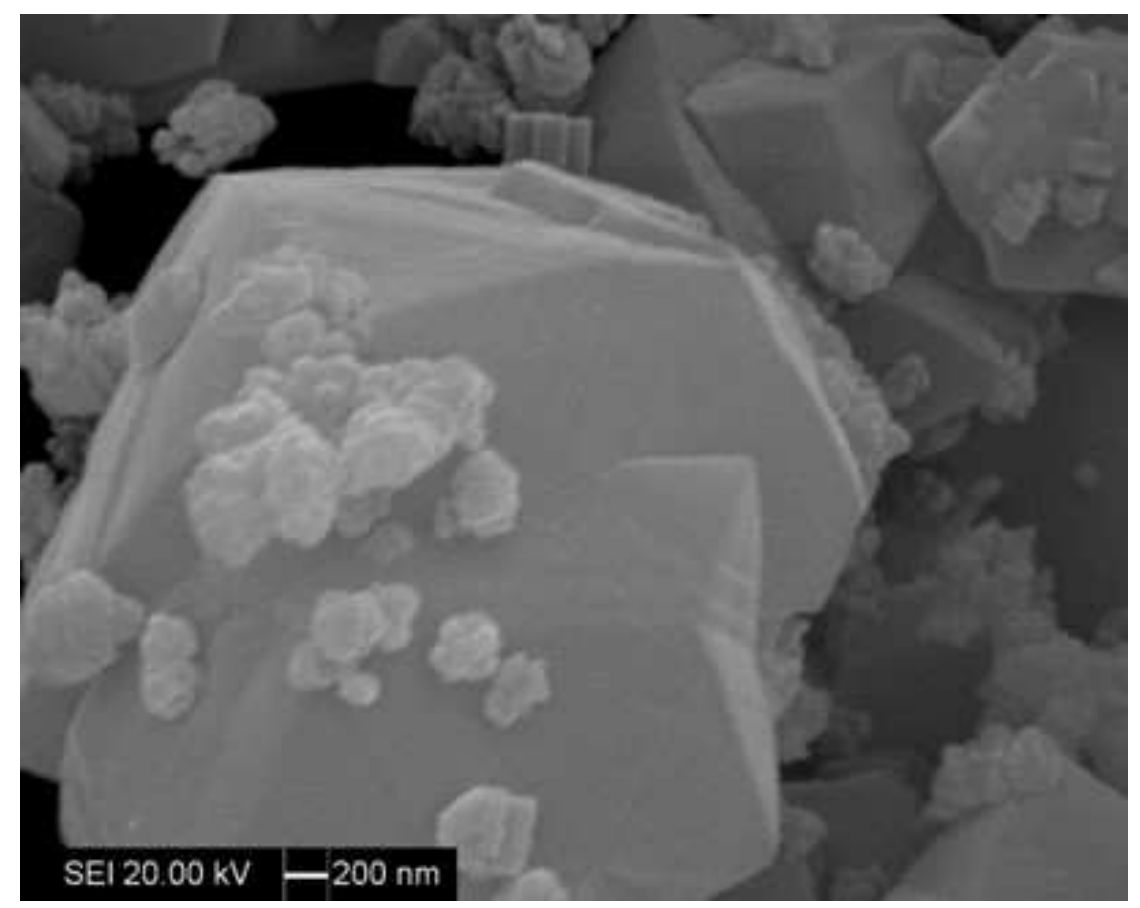

Figura 6 - Imagem ampliada dos cristais de Zeólita X. 


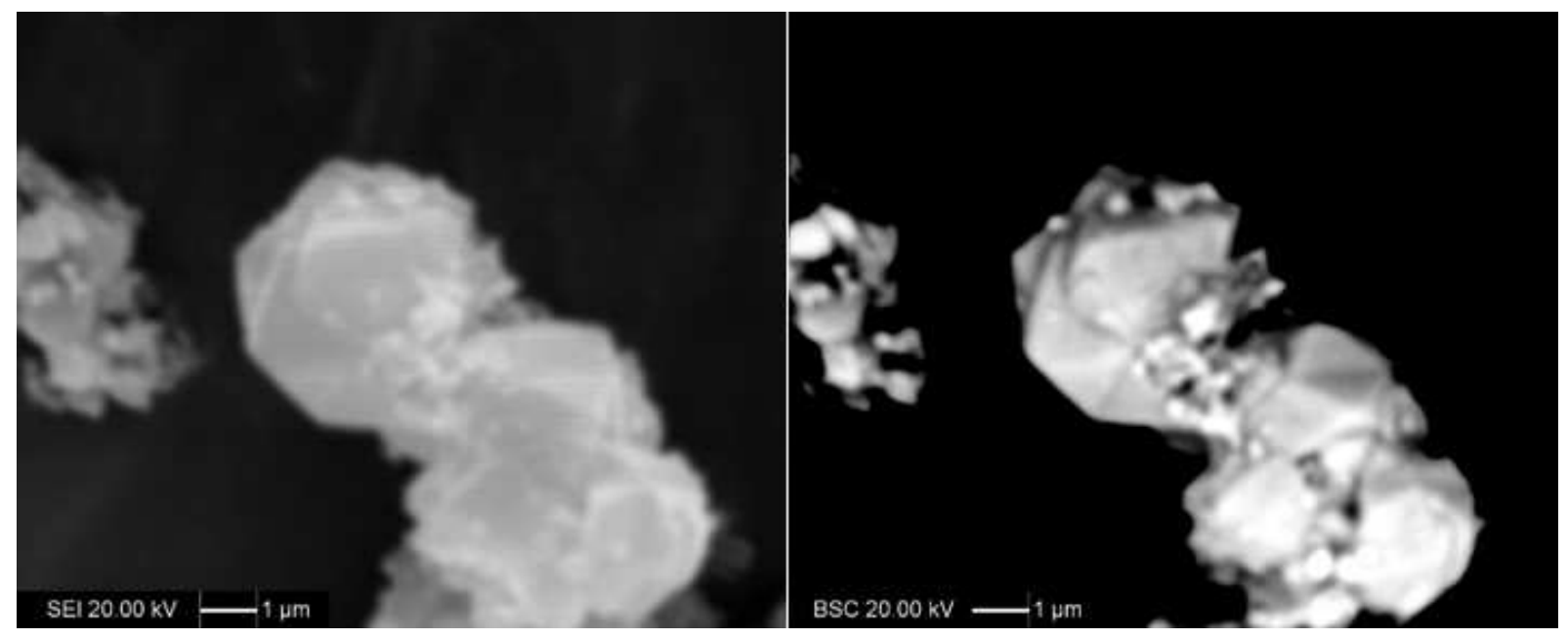

Figura 7 - Imagem de elétrons secundários a esquerda, e por elétrons retro espalhados a direita, de zeólita $\mathrm{X}$ contendo carbono funcionalizado antes da calcinação.

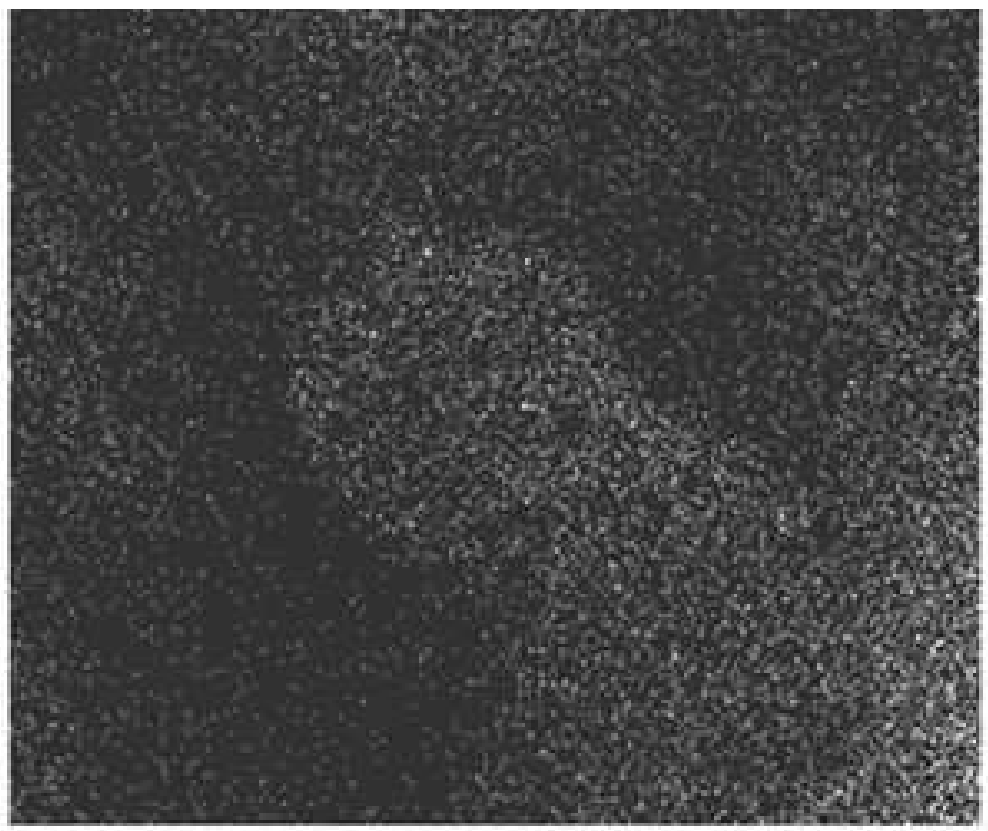

\section{CKa1_2}

Figura 8 - Imagem de raios-X de amostra de zeólita X sintetizada com carbono funcionalizado, indicando a intensidade relativa de carbono na imagem.

\section{CONCLUSÕES}

Com base no planejamento estatísitco de Placket e Burman, dentre as variáveis estudadas, as que apresentaram maior efeito na cristalinidade avaliada por medidas de adsorção foram o tempo de cristalização da zeólita, a ordem de mistura das soluções reagentes sendo que a solução de aluminato deve ser adicionada sobre a solução de silicato de sódio num tempo pequeno entre 30 e 60 segundos.

Experimentos específicos mostraram que partículas de carbono funcionalizadas (com 
ácido nítrico ou peróxido de hidrogênio) não entram nos cristais. Outrossim, as partículas de carbono, possivelmente pelo caráter ácido, interferem negativamente na síntese de zeólita $\mathrm{X}$, diminuindo o teor de zeólita $\mathrm{X}$ cristalina e causando o aparecimento de cristais de zeólita A.

Recomenda-se a repetição dos experimentos com estruturas mais estáveis a calcinação tal como a zeólita Y que pode ser calcinada em temperaturas maiores que $500{ }^{\circ} \mathrm{C}$ sem a ocorrência de colapso estrutural.

\section{AGRADECIMENTOS}

Ao Centro Universitário FEI pelo suporte para o desenvolvimento do trabalho.

\section{REFERÊNCIAS}

BAERLOCHER, H C.; MCCUSKER, L.B.; OLSON, D.H. Atlas of Zeolite Framework Types. 6. ed. Amsterdam, Elsevier, 2007.

BENESI, H.A.; Determination of Zeolite Contents of Zeolitic Catalysts from Vaporization Measurement. Journal of Catalysis, [S.1.] v.38, p.307-311, 1975.

BRECK, D. W. Zeolite Molecular Sieves. New York, Wiley, 1974.

CABOT CORPORATION, Technical Report S-131: Carbon Black Dispersion. Billerica, Mass, November, 1989.

CARMO, M.; et al.; A novel electrocatalyst support with proton conductive properties for polymer electrolyte membrane fuell cell applications. Journal of Power Sources. [S.1.] v. 191, N.2, p.330-337, 2009.

CARMO, M.; LINARDI, M.; POÇO, J.G.R. Characterization of nitric acid functionalized carbon black and its evaluation as electrocatalyst support for direct methanol fuel cell applications. Applied Catalysis A General: [S.1.]; v. 355, p.132-138, 2009.

CARMO, M.; LINARDI, M.; POÇO, J.G.R.: H2O2 treated carbon black as electrocatalyst support for polymer electrolyte membrane fuel cell applications. International Journal of Hydrogen Energy. [S.1.] v.33, p.6289-6297, 2008

CARMO, M. Preparação, caracterização e avaliação de eletrocatalisadores suportados em carbono funcionalizado para aplicação em células a combustível tipo PEMFC. Tese apresentada ao Instituto de pesquisas Energéticas e Nucleares (Autarquia Associada à Universidade de São Paulo) para obtenção do título de Doutor, São Paulo, 2008.

CASSA, J.C.S. Seleção de variáveis pelo processo e programação de experimentos pela abordagem estatística de Plackett-Burman. In: Anais do $\mathbf{1}^{\mathbf{}}$. Congresso Brasileiro de Engenharia Química, ABEQ, São Paulo, 1976. p.10.

CHRISTENSEN, C.H.; PÉREZ-RAMIREZ, J.; EGEBLAD， K.; GROEN, J.C., Hierarchical zeolites: enhanced utilisation of microporous crystals in catalysis by advances in materials design. Chem. Soc. Reviews, London, v. 37, n.11, p.2530-2542. 2008.

CHUNG, F. H.; SMITH, D.K. Industrial Applications of X-Ray Diffraction: Petroleum Catalysts. Boca Raton, CRC Press, 1999.

CORSO, C.; MAGALHÃES, F.S.; RESENDE, K.A.; HORI, C.E.; OLIVEIRA, K.D.; AVILA-NETO, C.N. Síntese de Estrutura Faujasita a partir de $\mathrm{Al}(\mathrm{OH})_{3}$ por planejamento de experimentos. Anais do XI Encontro Regional de Catálise, [Campinas] 2014. p.10. 
DETÍLIO, M.A. Estudo da Síntese da Zeólita ZSM-5 com oclusão de Carbono. Trabalho de conclusão de curso. UFSCAR. São Carlos, 2007.

EGBLAD, K. Chemical Design of Functional Nanomaterials: Ph. D. Thesis. Technical University of Denmark, [S.1.], 2008.

ERTL, G.; KNÖZINGER, H.; SCHÜTH, F.; WEITKAMP, J. Handbook of Heterogeneous Catalysis, 2. ed. Wiley VCH Verlag, Weinheim, 2008.

GIANETTO, Giuseppe. Zeolitas: Caracteristicas, Propriedades y Aplicaciones Industriales.. Caracas: Edit - Ed. Innov. Tecn., 1989.

JACOBSEN, C. J. H. et al. Mesoporous Zeolite Single Crystals. J. Am. Chem. Soc. [S.1.], v. 122, n.29, p.7116-7117, 2000.

PLACKETT, R. L.; BURMAN, J. P. The design of optimum multifactorial experiments. Biometrika, [S.1.], v.33, n.4, p.305-325, 1946

PLUTH, J. J.; SMITH, J. V. Crystal structure of boggsite, a new high-silica zeolite with the first. Three-dimensional channel system bounded by both 12- and 10-rings Amer. Mineral. [S.1.], v.75, p.501, 1990.

RODRIGUES, M.I.; IEMMA, A.F. Experimental Design Process Optimization. Boca Raton, CRC Press, 2015. p.195-245

SAND, L. B. and MUMPTON, F. A. Natural Zeolites, Occurrence, Properties, Use, Pergamon Press, Oxford - UK, 1978. p.135-350.

YANG, H AND DU, C. Synthesis and characterization of zeolite 4A-type desiccant from kaolin, American Mineralogist [S.1.], v.95, p.741-746, 2010.

\title{
THE EFFECT OF SOME VARIABLES AND PARAMETERS USED IN THE SYNTHESIS OF FAUJASITE Na-X
}

\author{
M. S. CASTRO ${ }^{1}$, W. M. FANTIM ${ }^{1}$, R. CONDOTTA ${ }^{1}$, E. L. GOMES ${ }^{2}$, J. G. R. POÇO ${ }^{1, *}$ \\ ${ }^{1}$ FEI University, Department of Chemical Engineering \\ ${ }^{2}$ Federal University of São Paulo, Department of Exact and Earth Science \\ *E-mail: jgrpoco@fei.edu.br
}

\begin{abstract}
Synthetic zeolites have found several industrial applications as components in heterogeneous catalysts due to its highly regular structure and micropores which have regular dimensions and high specific surface area. However, in many of the petrochemical applications, microporous structure imposes limitations on the diffusion of molecules of reactants and products and becomes a problem. Much research effort has been done in the synthesis of other zeolitic structures with wider micropores diameters or structures having mixed micro and mesoporous. In this study, an experimental design based on the Placket \& Burman statistical method was done with the purpose of select variables that has the larger effects on the synthesis of zeolite of type faujasita (FAU-X) with low molar SiO2/Al2O3. After establish the best conditions the effect of the introduction of funcionalized nano-sized carbon particles in the generation of mesoporous structures was verified.
\end{abstract}

KEYWORDS: Zeolite X; Plackett \& Burman; Synthesis parameters; Variable selection. 